Article

\title{
Numerical Estimation and Experimental Verification of Optimal Parameter Identification Based on Modern Optimization of a Three Phase Induction Motor
}

\author{
Hegazy Rezk 1,2,*(D), Asmaa A. Elghany ${ }^{3}$, Mujahed Al-Dhaifallah 4,*(D), \\ Abo Hashema M. El Sayed ${ }^{2}$ and Mohamed N. Ibrahim $5,6,7$ D \\ 1 College of Engineering at Wadi Addawaser, Prince Sattam Bin Abdulaziz University, \\ Al-Kharj 11991, Saudi Arabia \\ 2 Electrical Engineering Dept., Faculty of Engineering, Minia University, Al-Minya 61519, Egypt; \\ abouhashema@mu.edu.eg \\ 3 Electrical Engineering Department, Beni Suef University, Beni Suef 62521, Egypt; \\ asmaamohamed@eng.bsu.edu.eg \\ 4 Systems Engineering Department, King Fahd University of Petroleum \& Minerals, \\ Dhahran 31261, Saudi Arabia \\ 5 Department of Electrical Energy, Metals, Mechanical Constructions and Systems, Ghent University, \\ 9000 Ghent, Belgium; m.nabil@ugent.be \\ 6 FlandersMake@UGent-Corelab EEDT-MP, 3001 Leuven, Belgium \\ 7 Electrical Engineering Department, Kafrelshiekh University, Kafr El-Sheikh 33511, Egypt \\ * Correspondence: hr.hussien@psau.edu.sa (H.R.); mujahed@kfupm.edu.sa (M.A.-D.)
}

Received: 14 October 2019; Accepted: 20 November 2019; Published: 21 November 2019

\begin{abstract}
The parameters of electric machines play a substantial role in the control system which, in turn, has a great impact on machine performance. In this paper, a proposed optimal estimation method for the electrical parameters of induction motors is presented. The proposed method uses the particle swarm optimization (PSO) technique. Further, it also considers the influence of temperature on the stator resistance. A complete experimental setup was constructed to validate the proposed method. The estimated electrical parameters of a 3.8-hp induction motor are compared with the measured values. A heat run test was performed to compare the effect of temperature on the stator resistance based on the proposed estimation method and the experimental measurements at the same conditions. It is shown that acceptable accuracy between the simulated results and the experimental measurements has been achieved.
\end{abstract}

Keywords: particle swarm optimization; numerical parameter estimation; induction motor

\section{Introduction}

Induction motors (IMs) are employed extensively in several industrial applications because of their simple and rugged structure, easy operation and low cost maintenance. The induction motors can work direct online or via a controlled system. The main aim of using a control system for induction motors is to improve their dynamic performance. Several control techniques exist and are employed on induction motors, for example, vector control, direct torque control and sensorless control [1]. The electrical parameters of the motor are very essential to design, performance assessment, and feasibility of the control techniques. Therefore, it is very important to estimate the parameters of the electric motor accurately. Any difference between the actual motor parameters and those implemented in the drive system will significantly affect the system performance as well as the operation characteristics. Thereby, it is necessary to monitor the variation of the parameters during motor operation [2-4]. 
Most conventional techniques that are used to estimate the induction motor parameters require locked-rotor and no-load tests. However, such techniques cannot easily be applied due to mechanical rotor locking. In addition, in the locked rotor test, the rotor frequency is the same as the supply frequency; however, during operating conditions, the value of rotor frequency is lower than the supply. Therefore, such improper rotor frequency has an effect on locked rotor test results. In addition, in motors with high power, this test is impractical. These problems have encouraged researchers to investigate different procedures for motor parameter estimation. An analytical non-iterative method is presented in Reference [2] to estimate the parameters of the squirrel cage induction motor representing core losses from catalog or nameplate data. In Reference [3], the electrical parameters of squirrel cage and double-cage induction motors, considering and neglecting iron losses for both models by measuring current, voltage, rotor speed and electromagnetic torque, are identified. A review of parameter values estimation of three phase IMs based on information provided by manufacturers catalogs, in particular by those dedicated to efficiency estimation, has been presented in Reference [4].

Modern optimization has been used in different engineering applications like in References [5-8]. The idea of parameters estimation of electric machines is examined by several techniques like Particle Swarm Optimization (PSO), Extended Kaman filter (EKF) and Genetic algorithm (GA). For example, Reference [9] presents the application of PSO for estimating and tracking the changes of IM parameters using measured three phase currents, voltages and rotor speed. But this method applied 80 particle numbers and takes about 40 iterations to converge the actual values to the estimated ones. In Reference [10] an online estimation of IM parameters with Kalman filter is suggested, but the modelling errors cause state noise in the system. Rotor resistance and the time constant of IM are also identified using a fourth-order sliding-mode flux observer as presented in Reference [11] but high errors are obtained in their values when operating the motor at low torques. Moreover, rotor and stator resistances online estimation, using adaptive observer while motor speed and one phase current are available and high observer gains, are applied to achieve observer stability [12]. A GA is employed to estimate the values of the parameters of squirrel cage IM through some experimental data sets in Reference [13]. GA is also used in References [14-17] for determining the parameters of IM based on the manufacturer's published data. The Particle Swarm Optimization (PSO) algorithm is employed to determine the parameters of inductions motors in several publications, for example, References [18-21].

In this paper, a PSO algorithm for estimating the electrical parameters of IM is presented. In addition, a comparison between the performance of the IM based on the measured and estimated parameters using the PSO algorithm is provided. Moreover, a heat run test is performed to study the effect of temperature on the stator circuit and compare it with that obtained using the proposed PSO at the same conditions. The manuscript has been organized in two main sections; Section 2 presents induction motor parameters estimation based on PSO algorithm; Section 3 shows the results and discussion using both simulations and experimental systems.

\section{IM Parameter Determination Based on PSO Algorithm}

The electrical equivalent circuit of the IM at steady-state is shown in Figure 1. In this circuit, five electrical parameters are required to simulate the performance of the machine. The five parameters are the stator and rotor resistances $\left(R_{s}\right.$ and $\left.R_{r}\right)$, stator and rotor leakage inductances $\left(L_{l s}, L_{l r}\right)$ and magnetizing inductance $\left(L_{m}\right)$ [17-23].

In order to estimate these five parameters, a modified PSO technique is proposed hereafter. The PSO algorithm depends on the behavior of a bird's motion searching for food to trace its evolution. It has a figure of particles to generate a swarm. For a PSO system, the particles try to adjust their position depending on its own knowledge and the knowledge of neighboring particles and use the best position obtained from themselves and their neighbors [24]. 
Assume $X$ and $V$ are the particle's position and its consistent velocity in the search space respectively. At iteration $k$, the particle's position and velocity could be estimated from the following equations:

$$
\begin{gathered}
V_{i}(k+1)=W V_{i}(k)+C_{1} \beta_{1}\left(P_{i}(k)-X_{i}(k)\right)+C_{2} \beta_{2}\left(P_{g}(k)-X_{i}(k)\right) \\
x_{i}(k+1)=x_{i}(k)+V_{i}(k)
\end{gathered}
$$

where $k$ is the iteration step, $i$ is the particle, $W$ denotes the weight factor, $C_{1}$ and $C_{2}$ are constants used to scale the contribution of the cognitive and social components, respectively, $\beta_{1}$ and $\beta_{2}$ denote random values [0-1] by which stochastic elements are introduced in the algorithm and these parameters do not depend on time; $P_{i}$ and $P_{g}$ are the best position of the individual's and of the group's respectively.

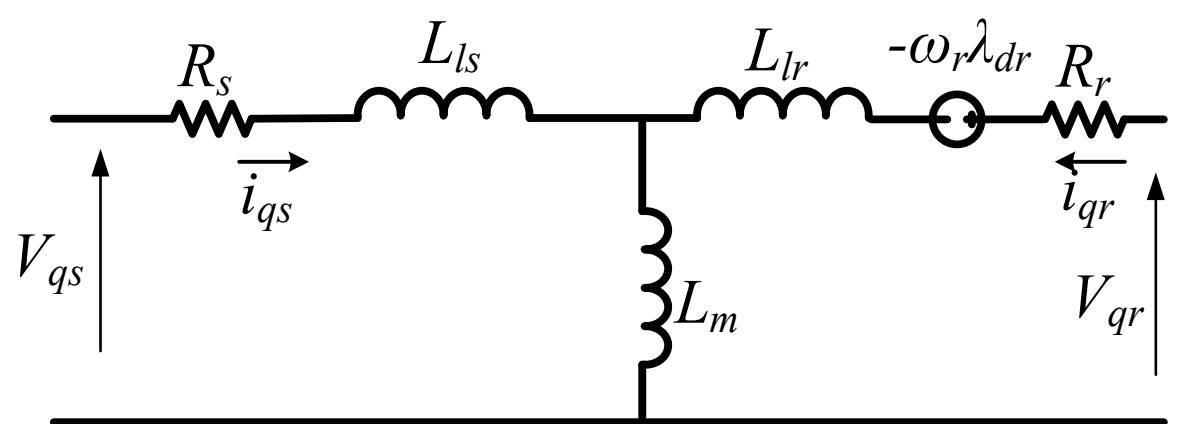

(a)

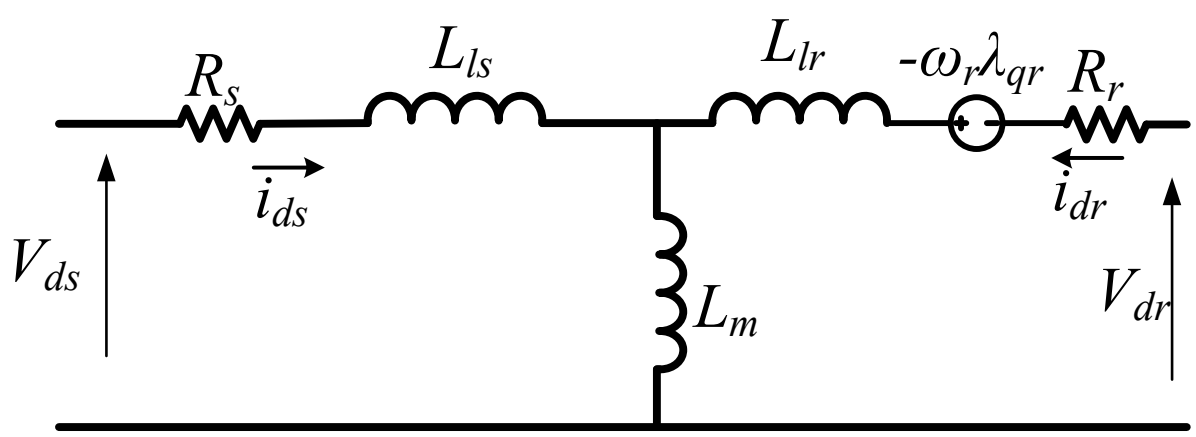

(b)

Figure 1. Equivalent circuit of induction motor (IM) in in stationary reference frame ((a) q-axis and (b) d-axis).

\subsection{Parametric Characterization}

Considering a system has an input $u$ and an output $y$. We can use the following state space form to describe the induction motor model.

$$
\begin{gathered}
\dot{x}=A x+B u \\
y=C x
\end{gathered}
$$

where: $x$ is states vector, $u$ is input vector, and $y$ is output vector as follows:

$$
\begin{gathered}
x=\left[\begin{array}{c}
\lambda_{d s} \\
\lambda_{q s} \\
\lambda_{d r} \\
\lambda_{q r}
\end{array}\right] u=\left[\begin{array}{l}
V_{d s} \\
V_{q s}
\end{array}\right] y=\left[\begin{array}{c}
i_{d s} \\
i_{q s} \\
i_{d r} \\
i_{q r}
\end{array}\right] B=\left[\begin{array}{ll}
1 & 0 \\
0 & 1
\end{array}\right] \\
A=E * C
\end{gathered}
$$




$$
\begin{aligned}
C & =\left[\begin{array}{cccc}
L_{l s}+L_{m} & 0 & L_{m} & 0 \\
0 & L_{l s}+L_{m} & 0 & L_{m} \\
L_{m} & 0 & L_{l r}+L_{m} & 0 \\
0 & L_{m} & 0 & L_{l r}+L_{m}
\end{array}\right]^{[-1]} \\
E & =\left[\begin{array}{cccc}
-R_{s} & 0 & 0 & 0 \\
0 & -R_{s} & 0 & 0 \\
0 & \omega_{r} L_{m} & -R_{r} & \omega_{r}\left(L_{l r}+L_{m}\right) \\
\omega_{r} L_{m} & 0 & -\omega_{r}\left(L_{l r}+L_{m}\right) & -R_{r}
\end{array}\right]
\end{aligned}
$$

where $R_{s}$ and $R_{r}$ are the stator and rotor resistances, $L_{l s}$ and $L_{l r}$ are stator and rotor leakage inductances, $L_{m}$ is the magnetizing inductance, $V_{q s}, V_{d s}, V_{q r}$ and $V_{d r}$ are the $q$-axis and $d$-axis stator and rotor voltages respectively, $i_{q s}, i_{d s}, i_{q r}$ and $i_{d r}$ are the $q$-axis and $d$-axis stator and rotor currents respectively, $\lambda_{q s}, \lambda_{d s}, \lambda_{q r}, \lambda_{d r}$ are the q-axis and d-axis stator and rotor flux linkages and $\omega_{r}$ is the rotor speed.

The parameters of the actual induction motor are represented in a vector called " $\theta$ " which is as follows:

$$
\theta=\left[\begin{array}{c}
R_{s} \\
R_{r} \\
L_{m} \\
L_{r}
\end{array}\right] .
$$

Since $\theta$ is the unknown parameters vector and its value must be identified exactly, a modeled system similar to the actual one is constructed with the same initial condition $\hat{x}(0)=x_{0}$. From this description, the input $u$ is provided for the actual and the modeled systems as Equations (3) and (4). The states and outputs of the actual system are ascertained based upon the information of $u$, and the estimated parameters. $\hat{x}$ and $\hat{y}$ denote the states and the output of the model. To assess the parameters to be distinguished, the fitness function for this identification problem will be contrasted. To serve this purpose, the objective function can be formulated by way of [25]:

$$
\begin{gathered}
F(\hat{\theta})=\int_{0}^{T} e d t \\
e=k_{i d} e_{i d}^{2}+k_{i q} e_{i q}^{2} \\
e_{i d}=i_{d s}-i_{d s}^{\wedge} \\
e_{i q}=i_{q s}-i_{q s}^{\wedge}
\end{gathered}
$$

where $k_{i d}$ and $k_{i q}$ are suitable gains and $T$ is a suitable time.

The two values of $i_{d s}$ and $i_{q s}$ are used as inputs to the optimizer. The cost function represented by the square of the difference values between the real and estimated output. This cost function is minimized during the optimization process in order to find out the optimal parameters of IM. The cost function will be zero or minimized only if the estimated IM parameters nearly equal their actual ones, that is, $\hat{\theta}=\theta$, to simplify the identification process, the IM system model in Equation (3) must be discretized.

The configuration of the parameter identification methodology in this study is demonstrated in Figure 2. The steps of the optimization process are explained in Figure 3. First, the system input $u$ is known to the actual and modeled systems. After that, the outputs of them are compared and fed to a fitness function. Finally, the calculated value of this function is used as an input to the PSO identifier for the identification process. 


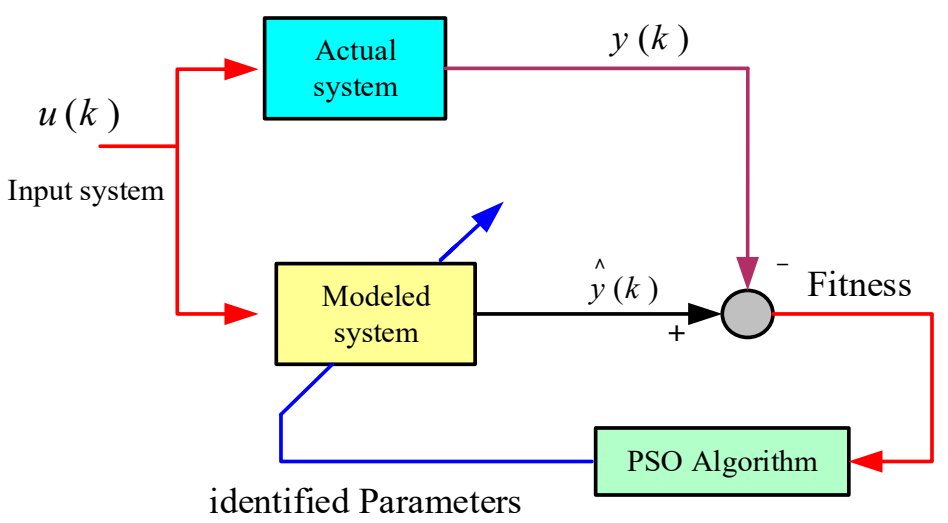

Figure 2. Block diagram of Particle Swarm Optimization (PSO) identification algorithm.

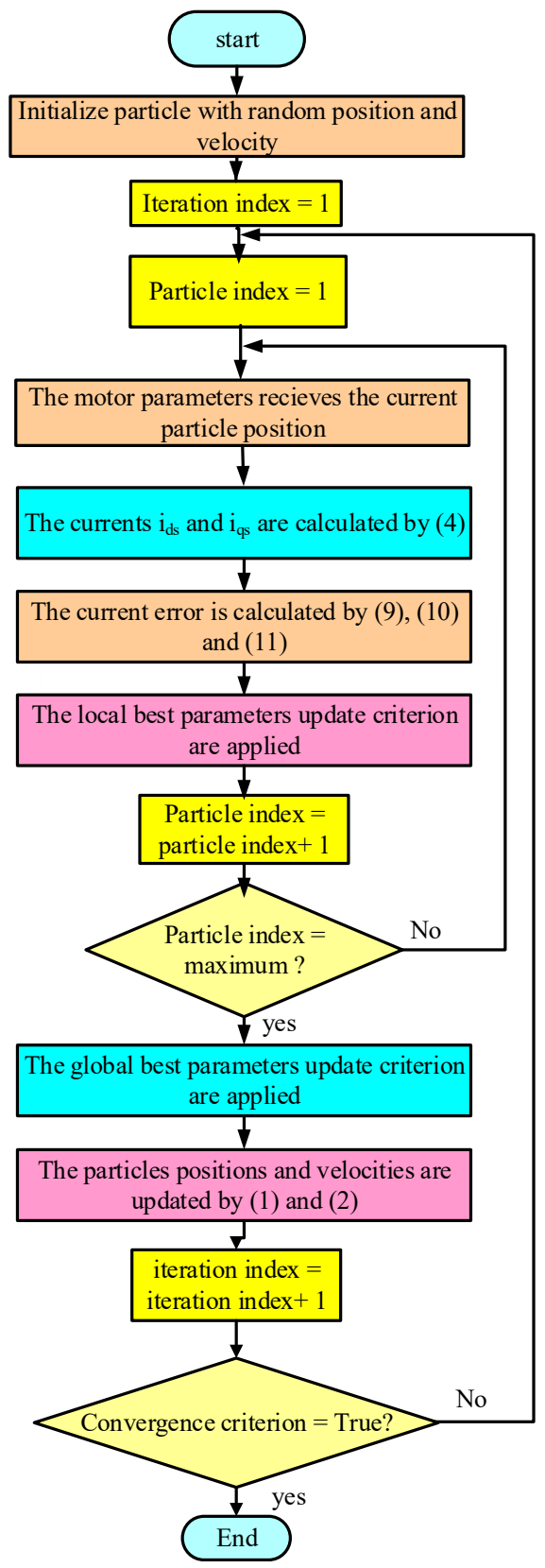

Figure 3. Flowchart of PSO algorithm. 
In order to apply the proposed optimization method to the IM model, a proper cost function is essential to be well-defined. From Equation (9), the currents $i_{d s}$ and $i_{q s}$ are the measurable values, and $\hat{i_{d s}}$ and $\hat{i_{q s}}$ are the estimated ones. $R_{r}, R_{s}, L_{m}$ and $L_{r}=L_{s}$ are the system's unknown parameters. To implement the PSO identification process for the squirrel cage IM, a particular Simulink model in MATLAB software program has been established.

During the optimization process, in order to identify the optimal values of IM parameters, the measured currents $i_{d s}$ and $i_{q s}$ for both the real and model system are set as inputs to the PSO. The errors between the real and estimated output signals are squared and selected to be the objective function.

\subsection{Non-Parametric Characterization}

For achieving steady state performance, studying these characteristics will be very essential and they are the stator current $\left(I_{S}\right)$, power factor $(p f)$, efficiency $(\eta)$, input power $\left(p_{i n}\right)$ and output power $\left(p_{\text {out }}\right)$. During this test, the IM is mechanically loaded with a DC generator of almost equal rating load and the stator current, rotor speed, the input and the output powers are measured. The overview of the virtual operation of the induction motor is illustrated in Figure 4.

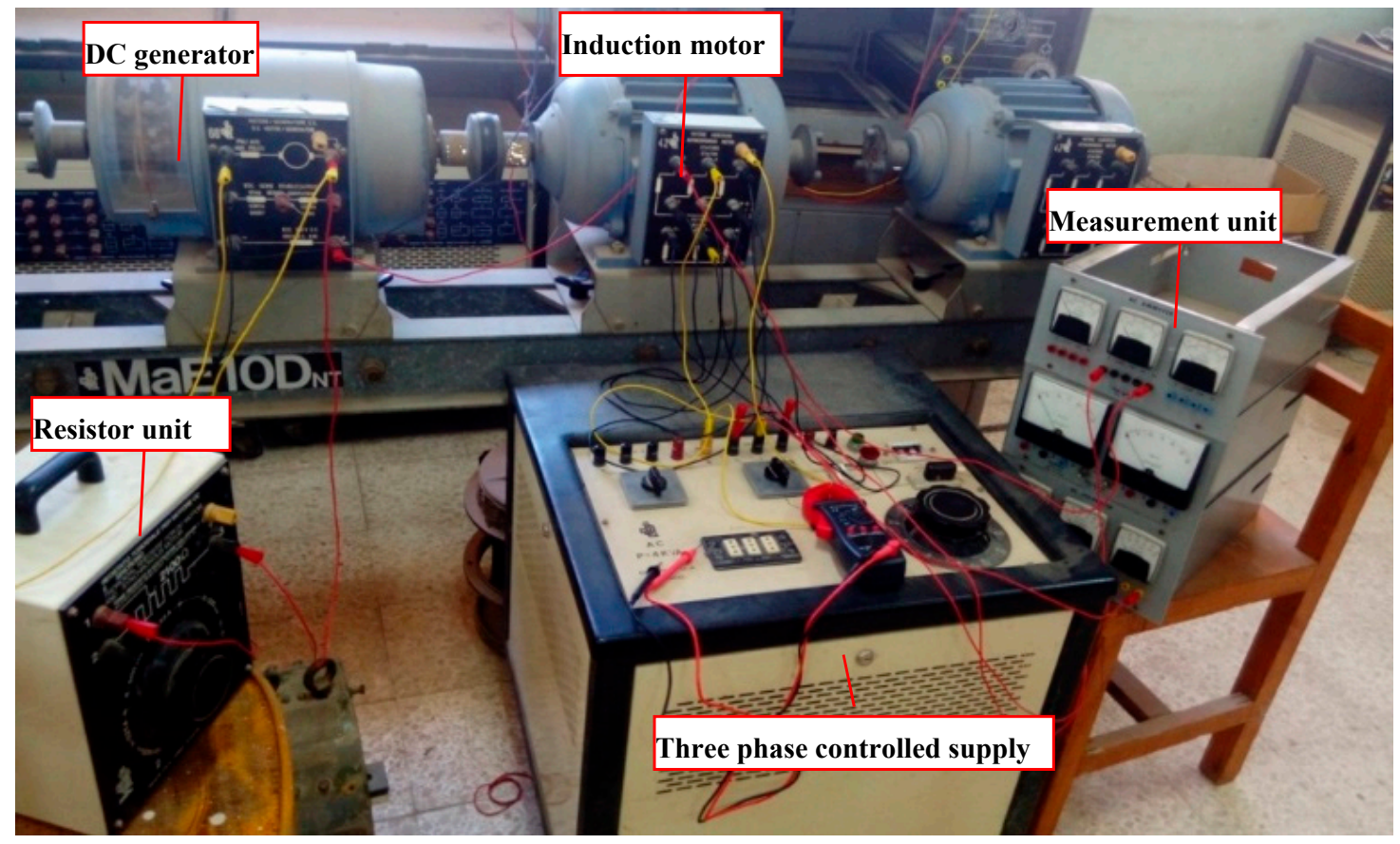

Figure 4. Photograph of the experimental setup.

\section{Results and Discussions}

\subsection{Characteristic of Induction Motor}

To display the performance of the proposed PSO algorithm, the complete model presented before is simulated using the Matlab environment. The simulation is performed at low speed of $100 \mathrm{rpm}$ and loading of 10 N.m. The estimated motor parameters are plotted versus iterations number as shown in Figures 5-8. The PSO algorithm runs with five particles in the swarm and 200 iterations. The stator resistance versus iterations number is plotted in Figure 5 and shows that the parameter tries to be identified at iteration 38. Further, when the stator resistance is increased by $50 \%$ from the nominal value (due to increasing the temperature of stator windings), the estimated value corresponds with the actual value only after 10 iterations. Similarly, the rotor resistance is reported in Figure 6, which shows that the algorithm has a reduced sensitivity and begins to precisely track the actual value within 
20 iterations. The prediction of magnetizing and stator inductances $\left(L_{m}\right.$ and $\left.L_{s}=L_{r}\right)$ are confirmed in Figures 7 and 8. It is clear that the PSO system converges faster with less fluctuation and greatly outperformed the others.

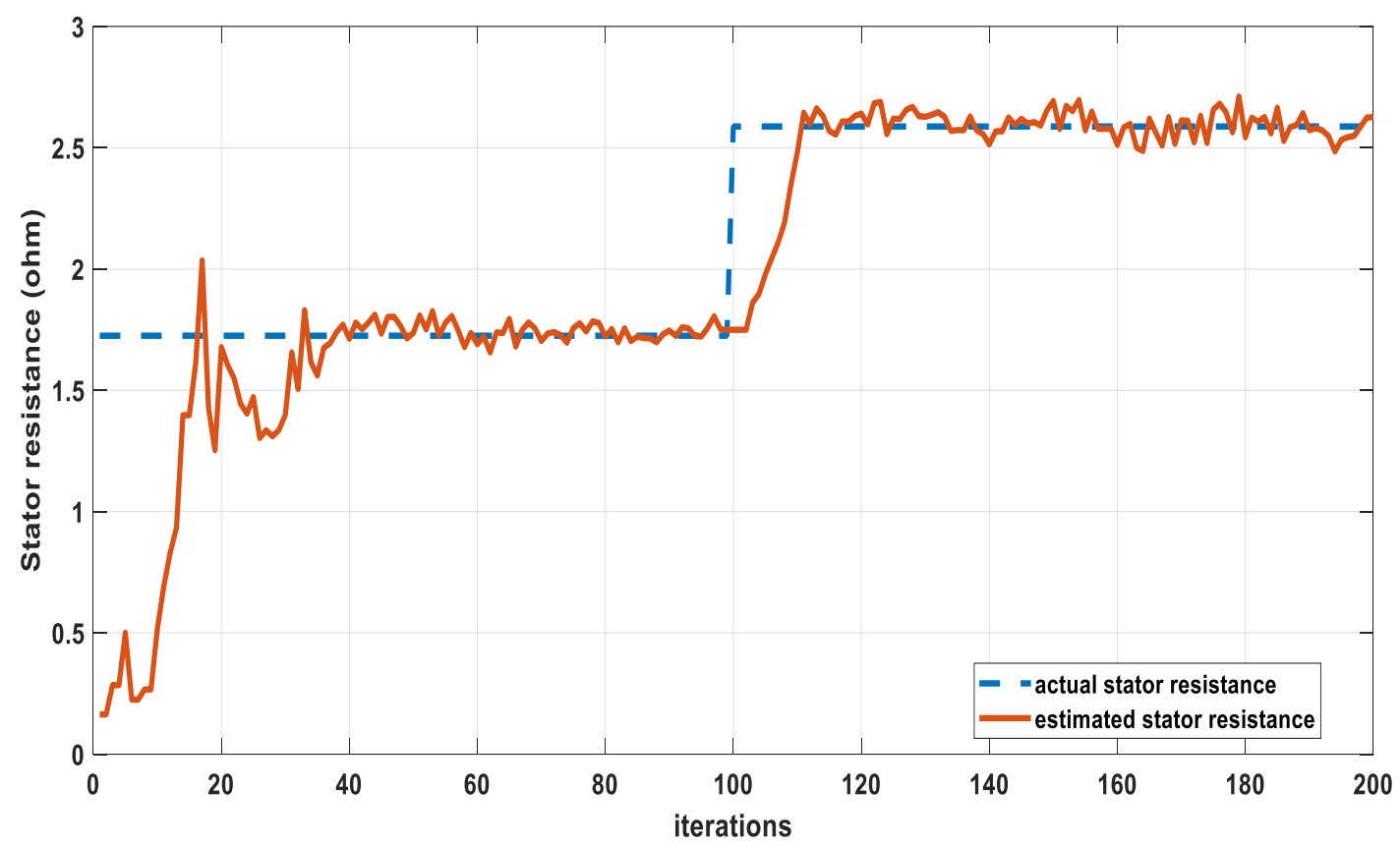

Figure 5. Stator resistance versus iteration numbers.

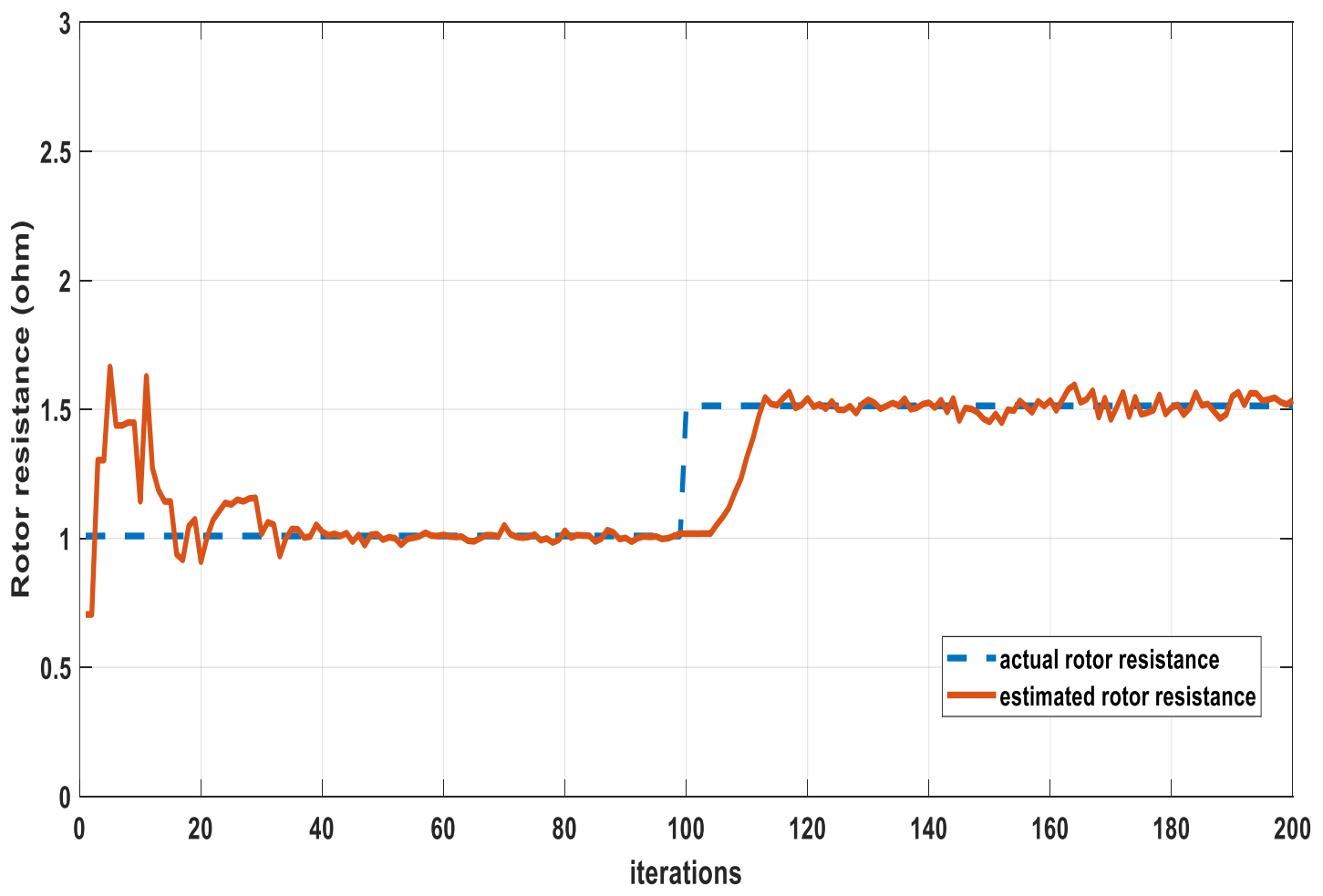

Figure 6. Rotor resistance versus iteration numbers. 


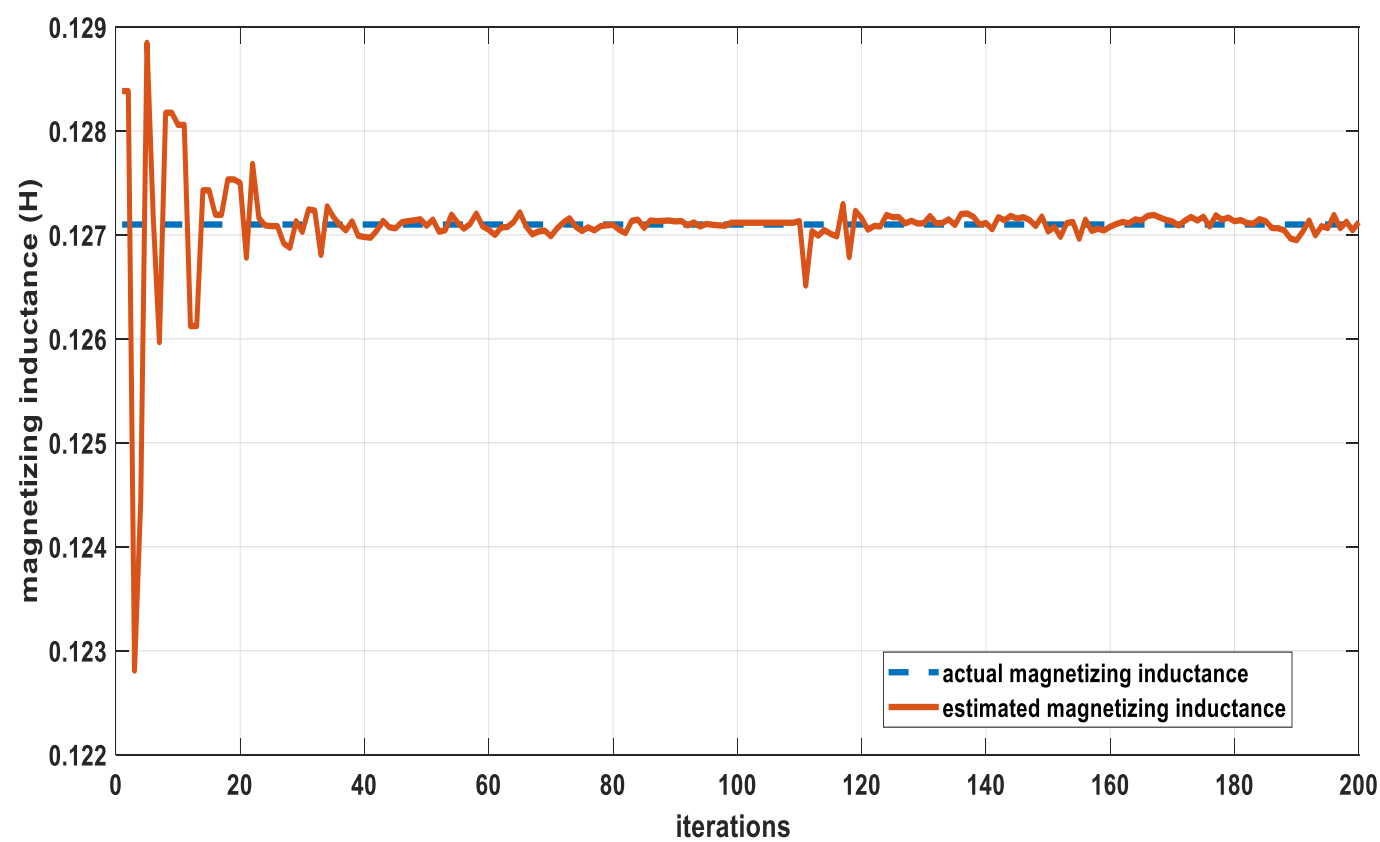

Figure 7. Magnetizing inductance versus iteration numbers.

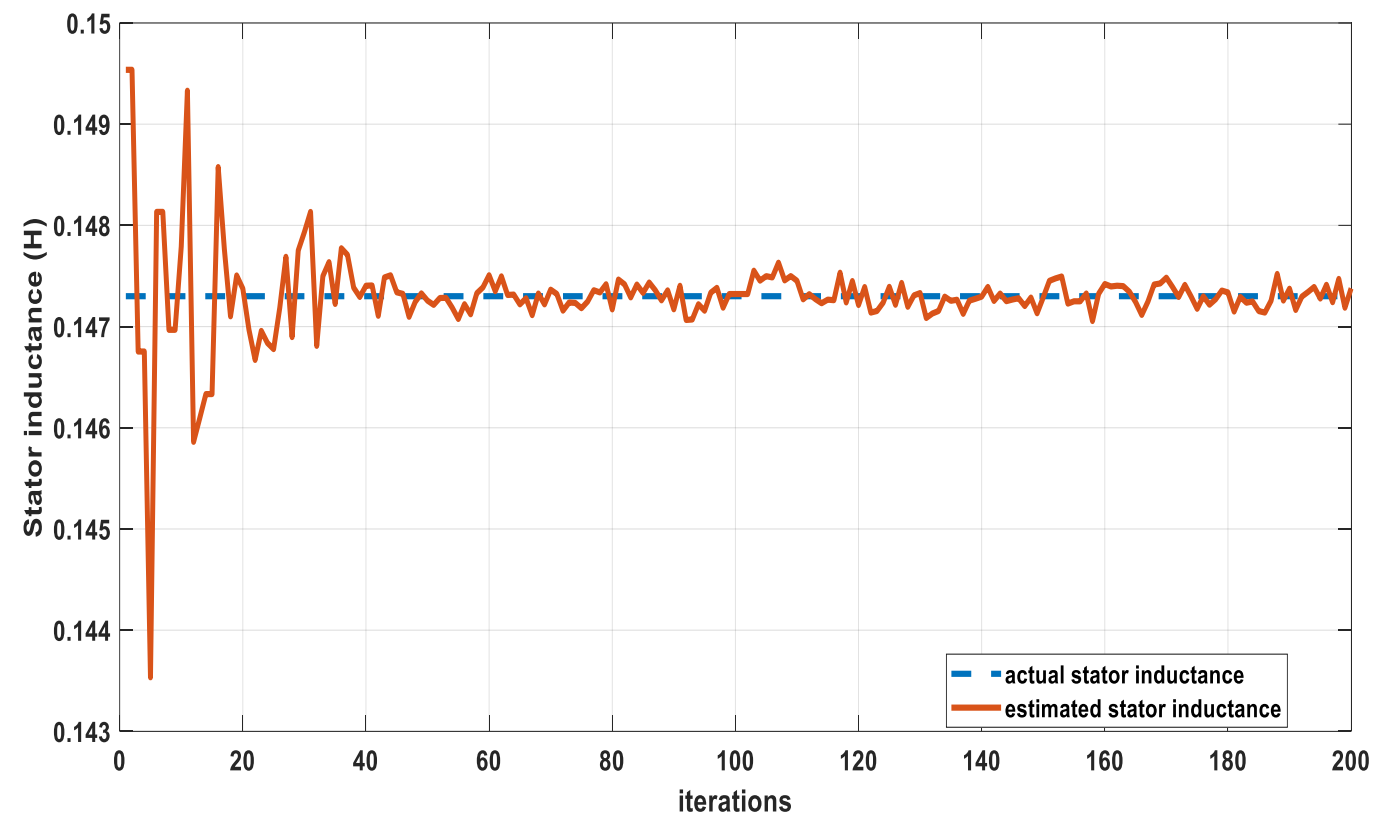

Figure 8. Stator inductance versus iteration numbers.

In this part, a comparison between three methods including performance depending on calculation based on standard data specification of the motor (see Appendix A), on data obtained from PSO system and finally on a direct loading test of the induction motor. To confirm the effectiveness of the proposed method in parameter identification, computer simulations which have been carried out using MATLAB software results will be compared with others from experimental tests. The motor data specifications are identical to those used in the simulation.

Figures 9-12 show the results obtained from the parameters and data specifications of the manufacturer, PSO algorithm and experimental measurements of the induction motor. Figures 9 and 10 show standard, estimated and experimental value of stator current and input power factor. These figures indicate that the estimated values are well matched and agree with their measured ones. On the other hand, the large deviation between the standard values of stator current and input power 
factor and their experimental ones is owed to the consideration that the parameters of the machine are assumed to be constant at all operating conditions.

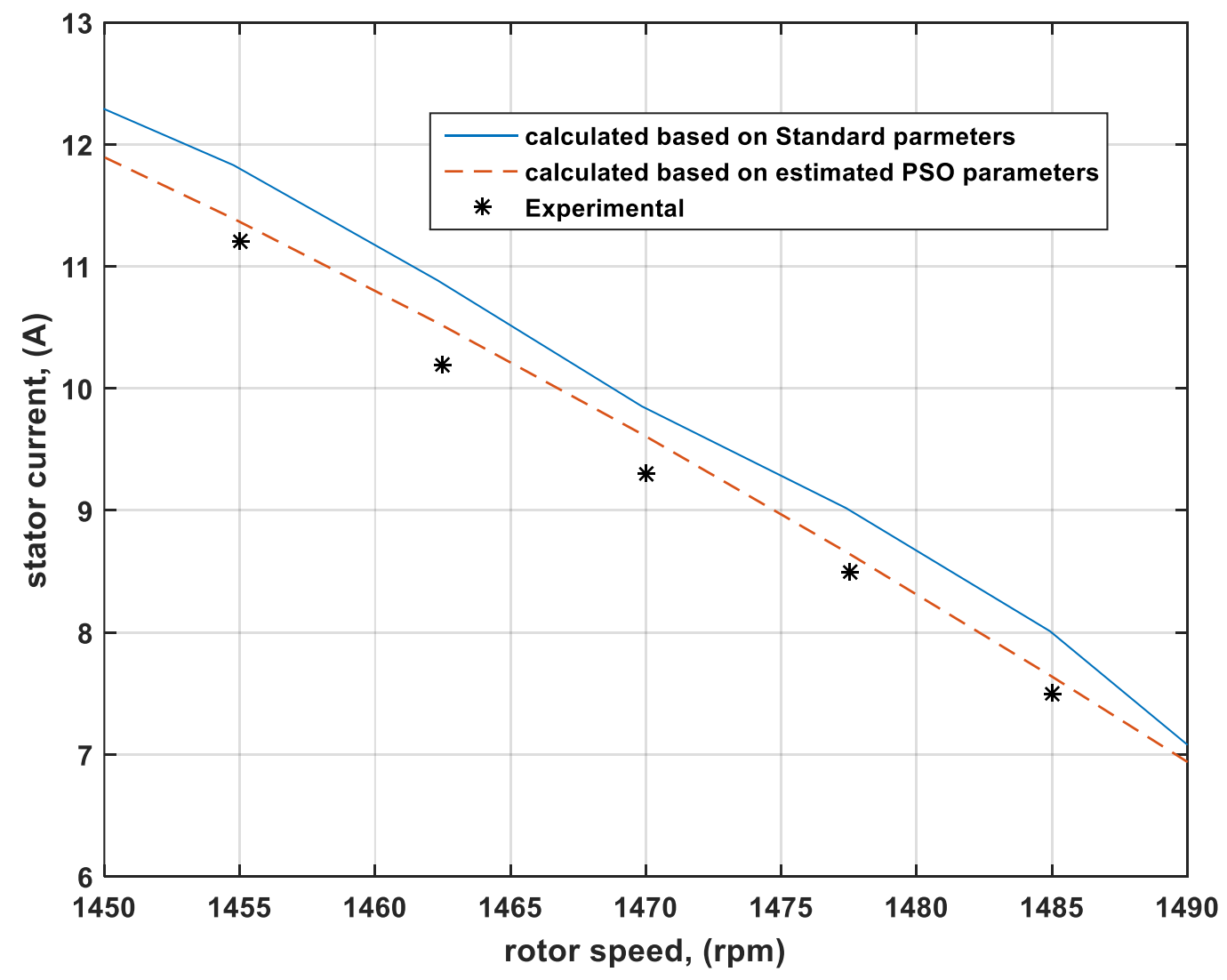

Figure 9. Variation of stator current versus motor speed.

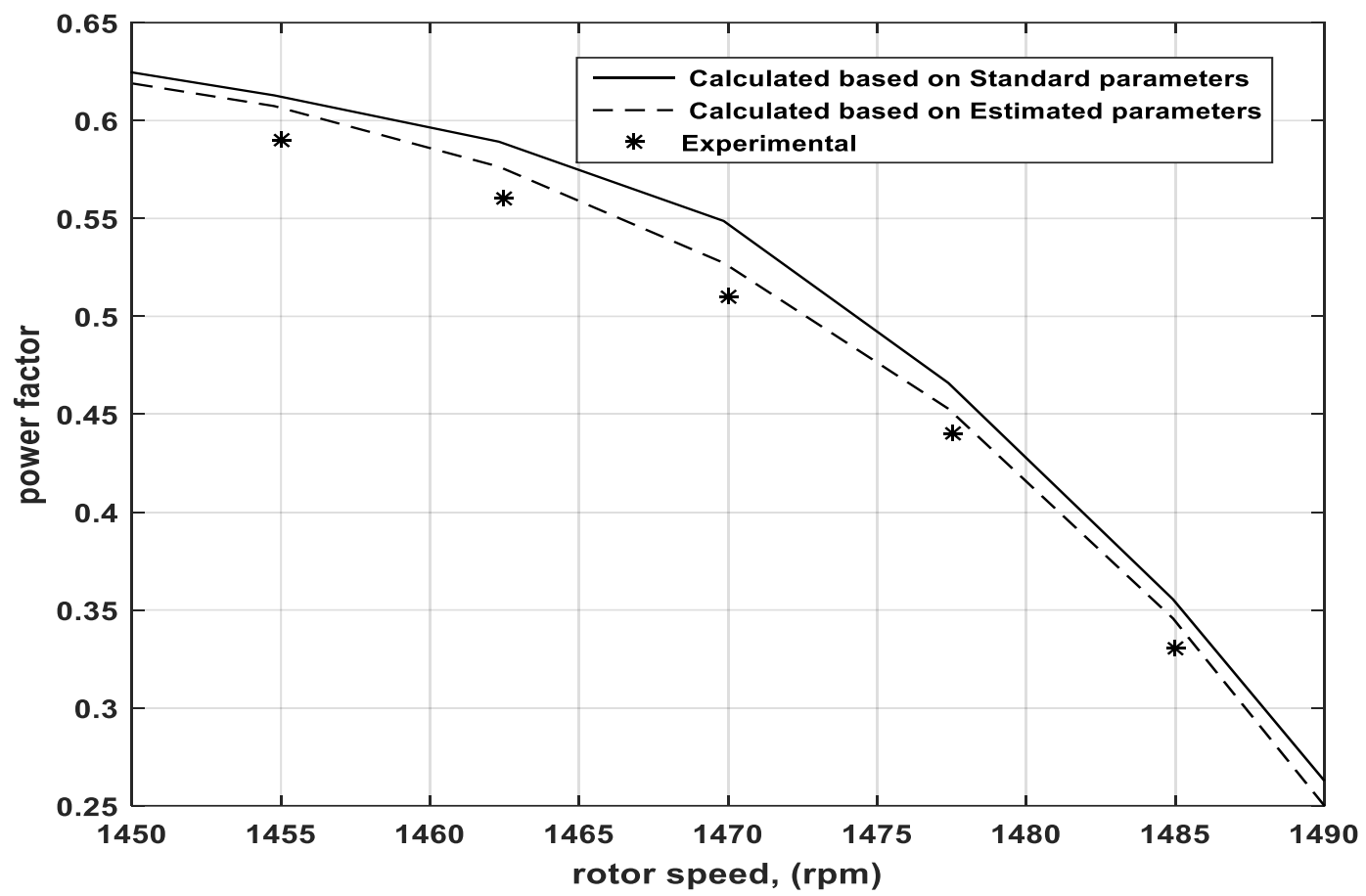

Figure 10. Variation of power factor versus motor speed. 


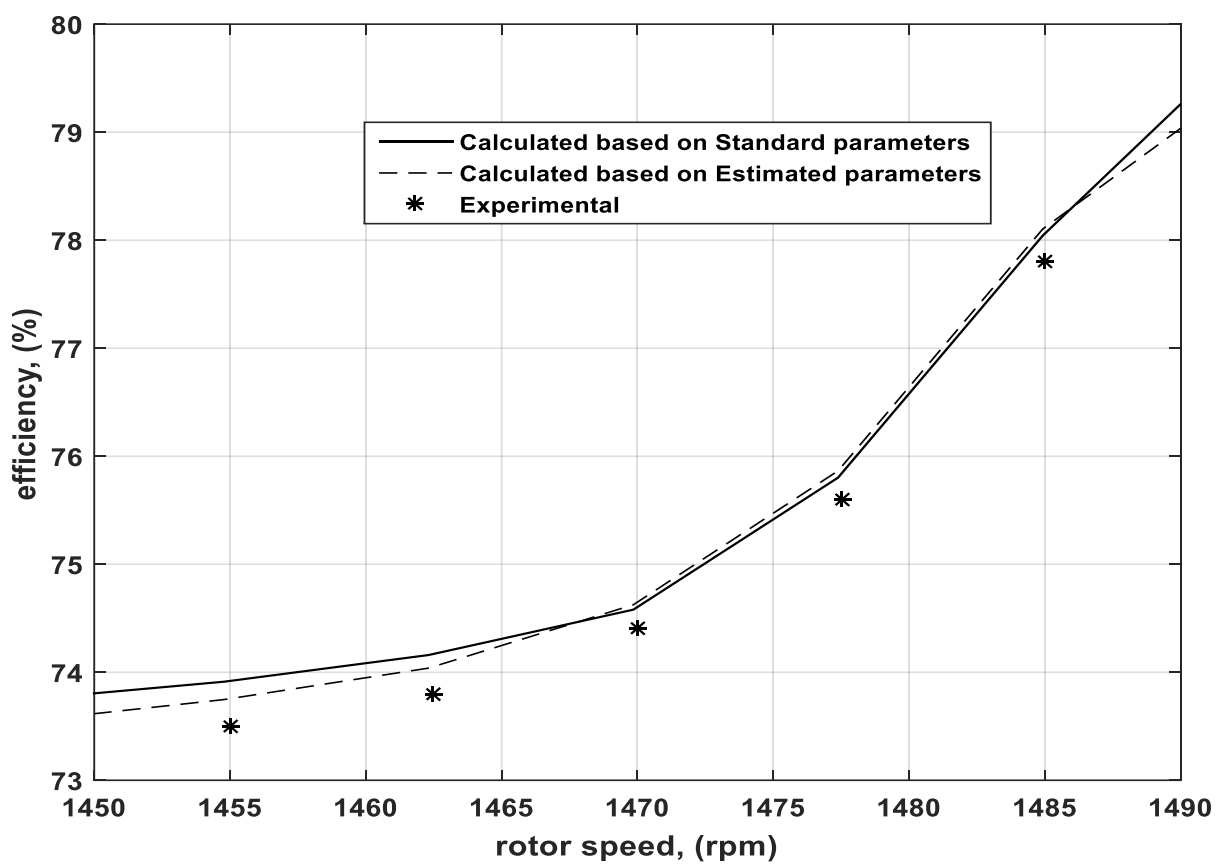

Figure 11. Variation of motor efficiency versus motor speed.

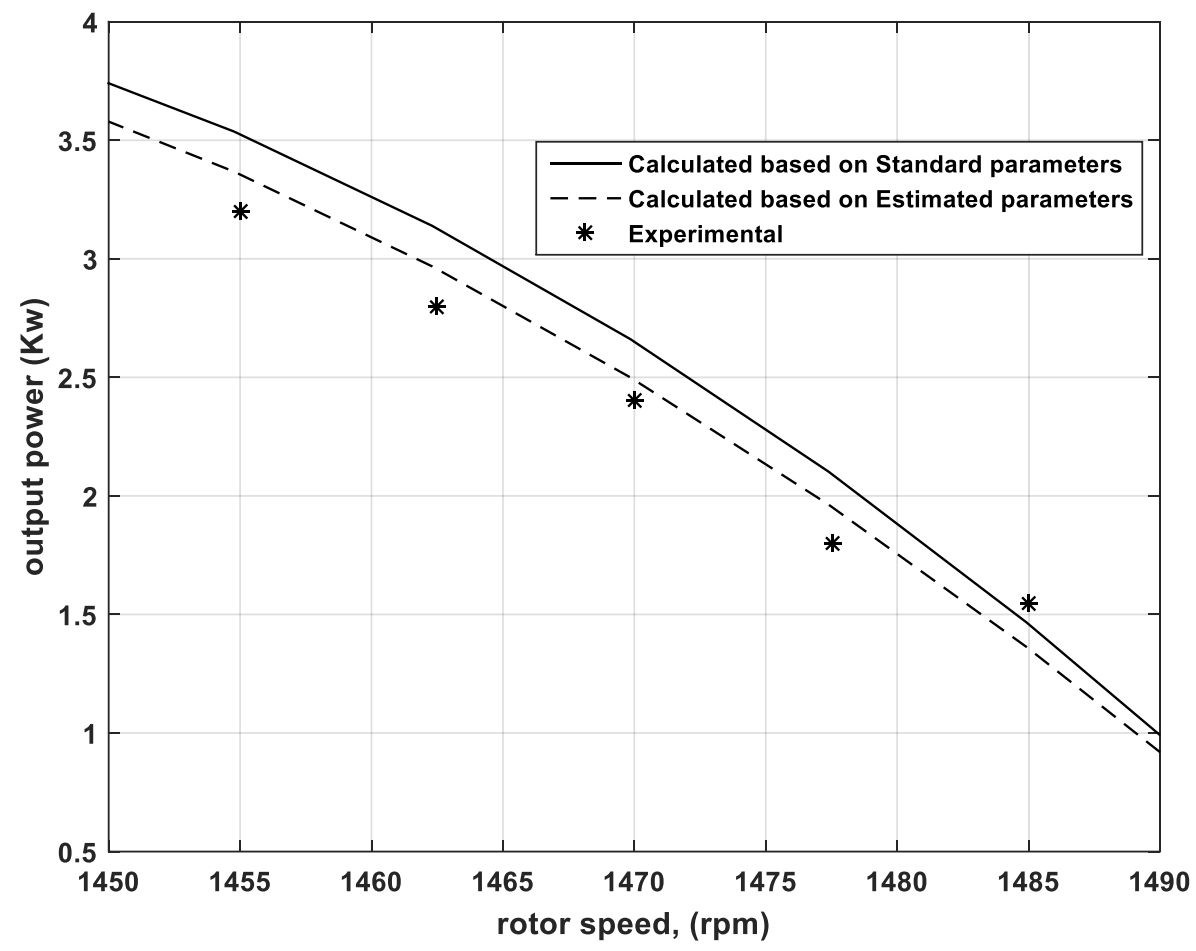

Figure 12. Variation of output power versus motor speed.

Figure 11 shows standard estimated and experimental values of the motor efficiency versus motor speed. From this figure, the estimated values of motor efficiency and the measured values have insignificant deviation and the discrepancy between estimated and experimental efficiency values especially at high values of motor speed is attributed to the mechanical loss, which has been disregarded from the equivalent circuit.

Figure 12 shows the standard, estimated and experimental values of the motor input and output power versus motor speed, respectively. From this figure, it is clear that the estimated values of both motor input and output power and measured values have small deviation. The discrepancy between 
estimated and experimental values, especially at high values of motor speed, is attributed to the mechanical loss and magnetization saturation, which is disregarded from the equivalent circuit.

From Figures 9-12, it can be seen that the values of estimated parameters provide good calculation of the performance characteristics of induction motor. This insures success of the presented procedure for motor parameter estimation.

Standard motor parameters obtained from standard tests (open and short circuit tests) and the estimated parameters obtained using the PSO algorithm are listed in Table 1. The third row in this table shows the percentage error results. These errors are small and are tolerated to get good parameters estimation.

Table 1. Estimated and Standard Induction Motor Parameters.

\begin{tabular}{ccccc}
\hline Electrical Parameter & $\boldsymbol{R}_{\boldsymbol{S}}(\boldsymbol{\Omega})$ & $\boldsymbol{R}_{r}(\boldsymbol{\Omega})$ & $L_{l r}=L_{l s}(H)$ & $L_{m}(H)$ \\
\hline Standard & 1.725 & 1.009 & 0.0202 & 0.1271 \\
\hline PSO & 1.7290 & 0.9322 & 0.0205 & 0.1271 \\
\hline Error|\%| & 0.232 & 7.6115 & 1.4851 & $\sim 0$ \\
\hline
\end{tabular}

\subsection{Temperature Influence on Stator Resistance}

To investigate the temperature effect on induction motor stator resistance at different loading conditions using the proposed estimation method, a heat run test was performed. The induction motor was run on 3 phase supply and loaded by a DC generator coupled to it as shown in Figure 4 . Different loading conditions were performed by adjusting load resistance across the DC generator. The motor was run for four hours at each load and after that time, and at motor standstill, the stator windings resistance were measured using the DC test but this measured value was multiplied by a factor to convert it from its DC value to its AC value. This is done to account for the skin effect.

The stator circuit resistance was estimated via PSO at different loading conditions and then compared with the measured values acquired from the heat run test. Figure 13 demonstrates that the values of stator circuit resistance, which have been obtained experimentally from the direct loading test, are in agreement with the estimated ones. The discrepancy between estimated and experimental values is attributed to the mechanical loss and magnetization saturation which have been neglected.

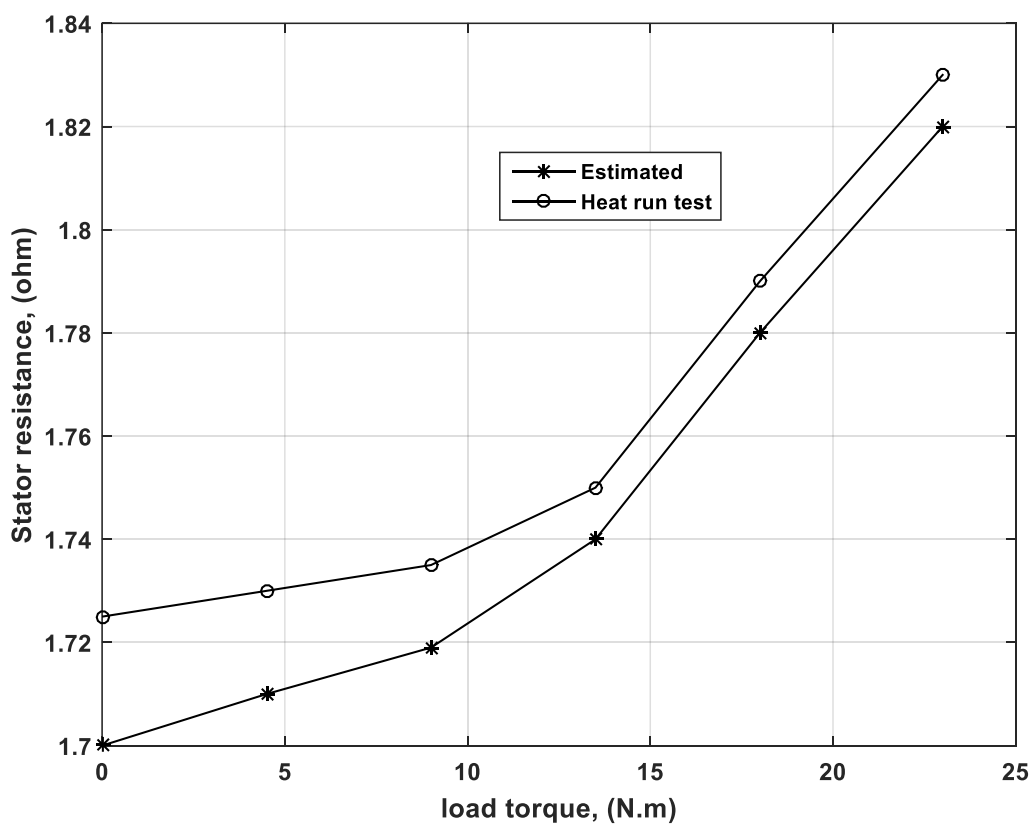

Figure 13. Stator resistance versus load torque at heat run test. 


\section{Conclusions}

An estimation method of induction motor electrical parameters based on the Particle Swarm Optimization (PSO) algorithm has been presented in this paper. Besides, comparison between the motor performance indicators, that is, power factor, efficiency and output power, obtained from experimental measurements and simulated based on the proposed parameters estimation method is provided. Moreover, the effect of temperature on the stator resistance is also shown. It is proved that the proposed estimation method of the motor parameters is capable of predicting an accurate motor performance, with an acceptable error. The main reason of the error is due to neglecting some effects on the implemented mathematical model of the induction motor such as mechanical losses and saturation of the magnetization inductance.

Finally, experimental measurements of the steady state performance and heat run test of the motor validate the theoretical results obtained using the proposed method.

Author Contributions: Conceptualization, methodology, software and writing-original manuscript, H.R., A.A.E. and M.N.I.; supervision and writing-review, M.A.-D. and A.H.M.E.S.; data curation, formal analysis, H.R., A.E.A. and M.N.I.

Funding: This research received no external funding.

Conflicts of Interest: The authors declare no conflict of interest.

\section{Appendix A}

Table A1. Parameters and data specifications of the induction motor.

\begin{tabular}{cc}
\hline Power (HP) & 3.8 \\
Voltage (V) & 380 \\
Current (A) & 8 \\
Frequency (Hz) & 50 \\
Stator resistance (ohm) & 1.725 \\
Rotor Resistance (ohm) & 1.009 \\
Stator inductance (H) & 0.1473 \\
Rotor inductance (H) & 0.1473 \\
Magnetizing inductance $(\mathrm{H})$ & 0.1271 \\
Rotor speed (rpm) & 1450 \\
\hline
\end{tabular}

\section{References}

1. Sarhan, H. Efficiency optimization of vector controlled induction motor drive. IJAET 2014, 7, 666-674.

2. Guimarães, J.M.C.; Bernardes, J.V.; Hermeto, A.E.; Bortoni, E.C. Determination of three-phase induction motors model parameters from catalog information. In Proceedings of the 2014 IEEE PES General Meeting/Conference \& Exposition, National Harbor, MD, USA, 27-31 July 2014; pp. 1-5.

3. Córcoles, F.; Pedra, J.; Salichs, M.; Sainz, L. Analysis of the induction machine parameter identification. IEEE Trans. Energy Convers. 2002, 17, 183-190. [CrossRef]

4. Wengerkievicz, C.A.; Elias, R.A.; Batistela, N.J.; Sadowski, N.; Kuo-Peng, P.; Lima, S.C.; Silva, P.A.D., Jr.; Beltrame, A.Y. Estimation of Three-Phase Induction Motor Equivalent Circuit Parameters from Manufacturer Catalog Data. J. Microw. Optoelectron. Electromagn. Appl. (JMOe) 2017, 16, 90-107. [CrossRef]

5. Mohamed, M.A.; Diab, A.A.Z.; Rezk, H. Partial shading shading mitigation of PV systems via different meta -heuristic techniques. Renew. Energy 2019, 130, 1159-1175. [CrossRef]

6. Al-Dhaifallah, M.; Nassef, A.M.; Rezk, H.; Nisar, K.S. Optimal parameter design of fractional order control based INC-MPPT for PV system. Sol. Energy 2018, 159, 650-664. [CrossRef]

7. Fathy, A.; Rezk, H. Multi-verse optimizer for identifying the optimal parameters of PEMFC model. Energy 2018, 143, 634-644. [CrossRef]

8. Abdalla, O.; Rezk, H.; Ahmed, E.M. Wind driven optimization algorithm based global MPPT for PV system under non-uniform solar irradiance. Sol. Energy 2019, 180, 429-444. [CrossRef] 
9. Tofighi, E.M.; Mahdizadeh, A.; Feyzi, M.R. Online estimation of induction motor parameters using a modified particle swarm optimization technique. In Proceedings of the IECON Proceeding Industrial Electronics Conference, Vienna, Austria, 10-13 November 2013; pp. 3645-3650.

10. Laroche, E.; Sedda, E.; Durieu, C. Methodological insights for online estimation of induction motor parameters. IEEE Trans. Control. Syst. Technol. 2008, 16, 1021-1028. [CrossRef]

11. Proca, A.B.; Keyhani, A. Sliding-mode flux observer with online rotor parameter estimation for induction motors. IEEE Trans. Ind. Electron. 2007, 54, 716-723. [CrossRef]

12. Salmasi, F.R.; Najafabadi, T.A. An Adaptive Observer With Online Rotor and Stator Resistance Estimation for Induction Motors With One Phase Current Sensor. IEEE Trans. Energy Convers. 2011, 26, 959-966. [CrossRef]

13. Bishop, R.R.; Richards, G.G. Identifying induction machine parameters using a genetic optimization algorithm. In Proceedings of the Southeastcon'90, New Orleans, LA, USA, 1-4 April 1990; IEEE: Piscataway, NJ, USA, 1990; pp. 476-479.

14. Pillay, P.; Nolan, R.; Haque, T. Application of genetic algorithms to motor parameter determination for transient torque calculations. IEEE Trans. Ind. Appl. 1997, 33, 1273-1282. [CrossRef]

15. Nangsue, P.; Pillay, P.; Conry, S.E. Evolutionary algorithms for induction motor parameter determination. IEEE Trans. Energy Convers. 1999, 14, 447-453. [CrossRef]

16. Alonge, F.; D'Ippolito, F.; Ferrante, G.; Raimondi, F. Parameter identification of induction motor model using genetic algorithms. IEE Proc. Control Theory Appl. 1998, 145, 587-593. [CrossRef]

17. Nolan, R.; Pillay, P.; Haque, T. Application of genetic algorithms to motor parameter determination. In Proceedings of the Conference Record-IEEE Industry Applications Society Annual Meeting, Denver, CO, USA, 2-5 October 1994; IEEE: Piscataway, NJ, USA; p. 47.

18. Nikranajbar, A.; Ebrahimi, M.; Wood, A. Parameter identification of a cage induction motor using particle swarm optimization. Proc. Inst. Mech. Eng. Part I J. Syst. Control Eng. 2010, 224, 479-491. [CrossRef]

19. Sahu, H.K. Two Phasing Method for Conducting Heat Run Test of Three Phase Induction Motors. In Proceedings of the International Conference on Advances in Electrical and Electronics (AEE 2010), Kerala, India, 21-22 December 2010.

20. Rezk, H.; Fathy, A. Simulation of global MPPT based on teaching-learning-based optimization technique for partially shaded PV system. Electr. Eng. J. 2017, 99, 847-859. [CrossRef]

21. Ibrahim, M.N.; Rezk, H.; Al-Dhaifallah, M.; Sergeant, P. Solar array fed synchronous reluctance motor driven water pump: An improved performance under partial shading conditions. IEEE Access 2019, 7, 77100-77115. [CrossRef]

22. Ibrahim, M.N.; Sergeant, P.; Rashad, E.M. Relevance of Including Saturation and Position Dependence in the Inductances for Accurate Dynamic Modeling and Control of SynRMs. IEEE Trans. Ind. Appl. 2017, 53, 151-160. [CrossRef]

23. Ibrahim, M.N.; Abdel-khalik, A.S.; Rashad, E.M.; Sergeant, P. An improved torque density synchronous reluctance machine with a combined star-delta winding layout. IEEE Trans. Energy Convers. 2018, 33, 1015-1024. [CrossRef]

24. Li, N.-J.; Wang, W.-J.; Hsu, C.-C.J.; Chang, W.; Chou, H.-G.; Chang, J.-W. Enhanced particle swarm optimizer incorporating a weighted particle. Neurocomputing 2014, 124, 218-227. [CrossRef]

25. Elghany, A.A.; Rezk, H.; el Sayed, A.H.M. Robust parameter estimation of vector controlled induction motors based on a modified particle swarm optimization technique. In Proceedings of the 2016 Eighteenth International Middle East Power Systems Conference (MEPCON), Cario, Egypt, 27-29 December 2016; pp. 171-178.

(C) 2019 by the authors. Licensee MDPI, Basel, Switzerland. This article is an open access article distributed under the terms and conditions of the Creative Commons Attribution (CC BY) license (http://creativecommons.org/licenses/by/4.0/). 